\title{
当院における大腸癌同時性肝転移症例の臨床病理学的検討
}

\author{
宮宗秀明*，岩川和秀，稲垣＼cjkstart優，木村祐司， \\ 西江学, 濱野亮輔, 徳永尚之, 常光洋輔, \\ 大塚眞哉，岩坦博已
}

国立病院機構福山医療センター 外科

\section{Clinical study of the prognostic factors in colorectal cancer patients with synchronous liver metastasis}

\author{
Hideaki Miyasou*, Kazuhide Iwakawa, Masaru Inagaki, Yuuji Kimura, \\ Manabu Nishie, Ryousuke Hamano, Naoyuki Tokunaga, Yousuke Tunemitsu, \\ Shinya Otsuka, Hiromi Iwagaki
}

Department of Surgery, National Hospital Organization Fukuyama Medical Center, Hiroshima 720-8520, Japan

\begin{abstract}
This study was aimed to clarify the prognostic factors in colorectal cancer patients with synchronous liver metastasis. Fifty-four patients were assessed to evaluate prognoses according to various clinico-pathological factors and therapeutic procedures. The patients' survival was significantly related to extrahepatic distant metastasis and therapeutic procedures. Regarding therapeutic procedures, the liver resection group showed significantly improved survival compared with the chemotherapy group, especially in liver metastasis Grade B. For colorectal liver metastases, it is clear that liver resection is the most effective treatment at present. Further improvement of patient prognoses is expected to be achieved by future research on combination chemotherapy .
\end{abstract}

キーワード：大腸癌 (colorectal cancer), 同時性肝転移 (synchronous liver metastasis), 肝切除 (liver resection), 化学療法 (chemotherapy)

\section{緒言}

Stage IV の進行大腸癌のうち, 肝転移巣に対する治療法 としては, 肝切除術, 全身化学療法, 肝動脈・門脈内抗癌 片注入療法等が試みられてきた。切除可能な肝転移巣に対 しては外科的切除が最も有効であることが認められてい る ${ }^{1)}$. 近年, FOLFOX/FOLFILI 導入や AVASTIN 等の分 子標的化学療法剤の併用により, 切除不能の同時性肝転移 症例に対しても化学療法を含めた積極的な治療が行われる ようになってきた。今回, 当院の過去 5 年間における大腸 癌同時性肝転移症例を治療法も含め, 臨床病理学的に検討 したので，若干の知見をもとに報告する.

\section{対象と方法}

2005 年 1 月から 2009 年 12 月までの 5 年間に当院外科で経 験した大腸癌同時性肝転移54例を対象とし, (1)壁深達度,

平成23年 6 月 17 日受理

* $7720-8520$ 広島県福山市沖野上町 4丁目14-17

電話：084-922-0001 FAX : 084-931-3969

E-mail : hidemiya777@yahoo.co.jp
(2)リンパ節転移, (3)腹膜播種, (4)遠隔転移, (5)肝転移分類, (6)Grade 分類, (7)治療法別分類（肝切除群：肝切除 + 化学 療法, 化学療法群：化学療法単独, 無治療群)についてそ れぞれ臨床病理学的に検討した。なお，患者背景について は表 1 に示した。肝切除群症例（肝切除十術前・術後化学 療法）の術式等については表 2 に示したが，肝転移巣同時 切除 (simultaneous resection： 1 期手術) が 6 例, 大腸切 除後肝転移巣切除（staged resection：2 期手術）が 5 例で あった。また，肝切除群においては，術後または術前後に 化学療法が施行されていた。化学療法の内容は様々で一定 の傾向はなく, 肝動注, 経口, 全身化学療法が重複して施 行されていた（表 3 )。当院では，可能であれば手術を第一 選択としており，大腸癌治療ガイドラインと同様，耐術可 能で，十分な残肝機能があり，肝転移巣が遺残なく切除可 能 (RFA も含む) で原発巣が制御されている場合に行って いる．肝門部リンパ節転移陽性を含む遠隔転移症例は肝切 除の適応から除外している。 また，肝切除群11例中 3 例に ラジオ波焼灼術（RFA）を併用した（表 2 ). RFA は切除 しきれない腫瘍に対して術中に併用した。手術適応外の症 例において，可能であれば基本的には化学療法を施行して 
表 1 患者背景

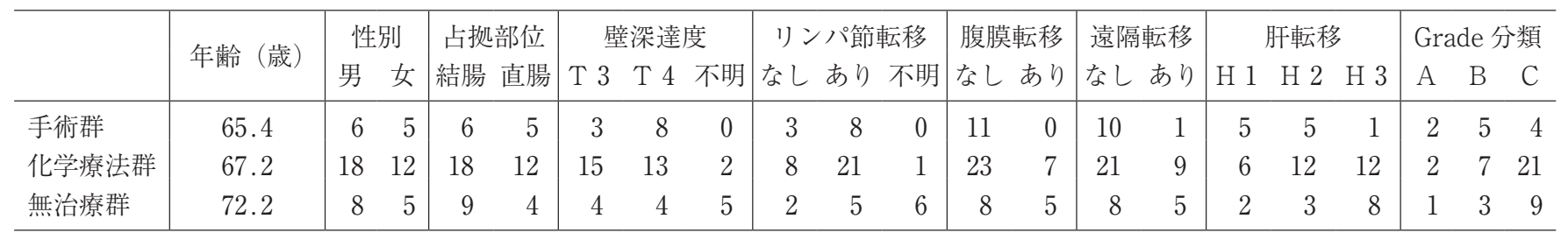

(手術群 : 肝切除 + 化学療法)

表 2 肝切除群症例

\begin{tabular}{|c|c|c|c|c|c|c|c|c|c|c|c|c|}
\hline 症例 & 年齢 & 性別 & $\mathrm{N}$ & $\mathrm{H}$ & $\mathrm{P}$ & M & Grade & 手術術式 & $1 \cdot 2$ 期 & RFA & 化学療法（肝切） & 生存 \\
\hline 1 & 40 & $\mathrm{M}$ & 0 & 3 & 0 & 0 & $\mathrm{C}$ & $\operatorname{Hr} 1(\mathrm{~L})$ & 2 期 & + & 術前後 & 生存 \\
\hline 2 & 71 & M & 2 & 2 & 0 & 0 & $\mathrm{C}$ & $\operatorname{Hr} 2(\mathrm{LM}), \operatorname{Hr} 0(\mathrm{~S} 8,6)$ & 2 期 & + & 術前後 & 生存 \\
\hline 3 & 65 & M & 1 & 2 & 0 & 0 & $\mathrm{~B}$ & $\operatorname{Hr} 1+(\mathrm{Pa}), \operatorname{Hr} 0(\mathrm{~S} 3)$ & 2 期 & + & 術前後 & 生存 \\
\hline 4 & 67 & $\mathrm{~F}$ & 0 & 1 & 0 & 0 & A & $\operatorname{Hr} 0(\mathrm{~S} 8)$ & 2 期 & & 術前後 & 生存 \\
\hline 5 & 67 & M & 4 & 1 & 0 & 1 & $\mathrm{C}$ & $\operatorname{Hr} 1(\mathrm{P})$ & 1 期 & & 術後 & 死亡 \\
\hline 6 & 70 & $\mathrm{~F}$ & 1 & 2 & 0 & 0 & $\mathrm{~B}$ & $\operatorname{Hr} 1+(\mathrm{PA}), \operatorname{Hr} 0(\mathrm{~S} 3)$ & 1 期 & & 術後 & 生存 \\
\hline 7 & 79 & $\mathrm{~F}$ & 2 & 1 & 0 & 0 & $\mathrm{~B}$ & $\mathrm{HrS}+(\mathrm{S} 8,4 \mathrm{~b})$ & 2 期 & & 術後 & 生存 \\
\hline 8 & 36 & $\mathrm{M}$ & 2 & 1 & 0 & 0 & $\mathrm{~B}$ & $\operatorname{HrS}(\mathrm{S} 5), \operatorname{Hr} 0(\mathrm{~S} 8)$ & 1 期 & & 術後 & 生存 \\
\hline 9 & 78 & M & 2 & 2 & 0 & 0 & $\mathrm{C}$ & Hr $2(\mathrm{AP})$ & 1 期 & & 術後 & 生存 \\
\hline 10 & 79 & $\mathrm{~F}$ & 1 & 1 & 0 & 0 & A & $\operatorname{Hr} 1$ (L) & 1 期 & & 術後 & 生存 \\
\hline 11 & 67 & $\mathrm{~F}$ & 0 & 2 & 0 & 0 & $\mathrm{~B}$ & $\operatorname{Hr} 2(\mathrm{AP})$ & 1 期 & & 術後 & 生存 \\
\hline
\end{tabular}

表 3 肝切除群化学療法レジメンの推移

\begin{tabular}{|c|c|}
\hline 症例 & 施行化学療法 \\
\hline 1 & 動注 $(5-\mathrm{FU}) \rightarrow \mathrm{UFT} \rightarrow$ FOLFOX $\rightarrow$ 肝切 $\rightarrow$ FOLFOX \\
\hline 2 & FOLFOX + bevacizumab $\rightarrow$ FOLFILI + bevacizumab $\rightarrow$ 肝切 $\rightarrow$ FOLFILI + bevacizumab \\
\hline 3 & FOLFOX $\rightarrow$ FOLFILI $\rightarrow$ 肝切 $\rightarrow$ 他院にて化学療法. \\
\hline 4 & $\mathrm{UFT}+\mathrm{LV} \rightarrow$ 消失 $\rightarrow$ 肝切 $\rightarrow \mathrm{TS}-1$ \\
\hline 5 & 肝切後, IFL $\rightarrow \mathrm{UFT}+\mathrm{LV} \rightarrow \mathrm{FOLFOX}$ \\
\hline 6 & 肝切後, Doxifluridine $\rightarrow$ 肝再発 $\rightarrow$ 動注 $(5-\mathrm{FU}) \rightarrow$ FOLFOX $\rightarrow$ FOLFILI \\
\hline 7 & 肝切後, UFT + LV $\rightarrow$ TS-1 \\
\hline 8 & 肝切後, IFL $\rightarrow$ 肝再発 $\rightarrow$ 動注 $(5-\mathrm{FU}) \rightarrow$ 肝切 $\rightarrow$ 動注 $(5-\mathrm{FU}) \rightarrow$ FOLFOX $\rightarrow$ FOLFIRI $\rightarrow$ FOLFIRI + bevacizumab \\
\hline 9 & 肝切後, UFT + LV $\rightarrow$ 肝再発 $\rightarrow$ FOLFOX $\rightarrow$ FOLFOX + bevacizumab \\
\hline 10 & 肝切後, UFT $+\mathrm{LV} \rightarrow \mathrm{CapOX}$ \\
\hline 11 & 肝切後, UFT + LV \\
\hline
\end{tabular}


いる. 化学療法群30例のレジメンの内訳についてはその詳 細を表 4 に示したが, FOLFOX 療法が最も多かった。な お, 生存率は Kaplan-Meier 法で算出し, log-rank testにて 有意差を検定した。また，進行度分類は大腸癌取扱い規約 第 7 版に基づいて行った。

表 4 化学療法群レジメンの内訳

\begin{tabular}{lc}
\hline \multicolumn{1}{c}{ レジメン } & 症例数 \\
\hline FOLFOX & 15 \\
FOLFOX + bevacizumab & 7 \\
UFT & 5 \\
FOLFIRI & 4 \\
UFT + LV & 4 \\
月干動注 (5-FU) & 3 \\
IFL & 3 \\
CPT-11 + cetuximab & 2 \\
Capecitabine & 2 \\
CapOx & 1 \\
5-FU + LV & 1 \\
TS-1 & 1 \\
\end{tabular}

※重複あり

\section{結果}

\section{1 . 臨床病理学的因子と生存率}

大腸癌同時性肝転移症例の予後を各種病理学的因子（壁 深達度, リンパ節転移, 腹膜播種, 遠隔転移, 肝転移分類, Grade 分類）で解析すると，統計学的に有意差が認められ たのは遠隔転移のみであった（図 1 )。

\section{2 . 治療法と生存率}

治療法別では肝切除群（肝切除十化学療法）が化学療法 群（化学療法単独）に比し有意に予後が延長した. Grade 分類に基づいた検討では, Grade B で化学療法群に比し肝 切除群で有意に予後が延長したが，Grade Cでは両群間に 有意差は認められなかった。いずれにおいても, 肝切除群, 化学療法群は無治療群に比し有意な予後の延長を認めた (図 2 , 表 5 )。

\section{考察}

大腸癌同時性肝転移症例の予後を臨床病理学的に解析す ると, 統計学的有意差が認められたのは遠隔転移のみで, リンパ節転移, 肝転移分類, Grade 分類では有意差は得ら れなかった（図 1 ). 当院の大腸癌同時性・異時性肝転移症 例に対する予後因子の検討では, 単変量解析では両葉転移,
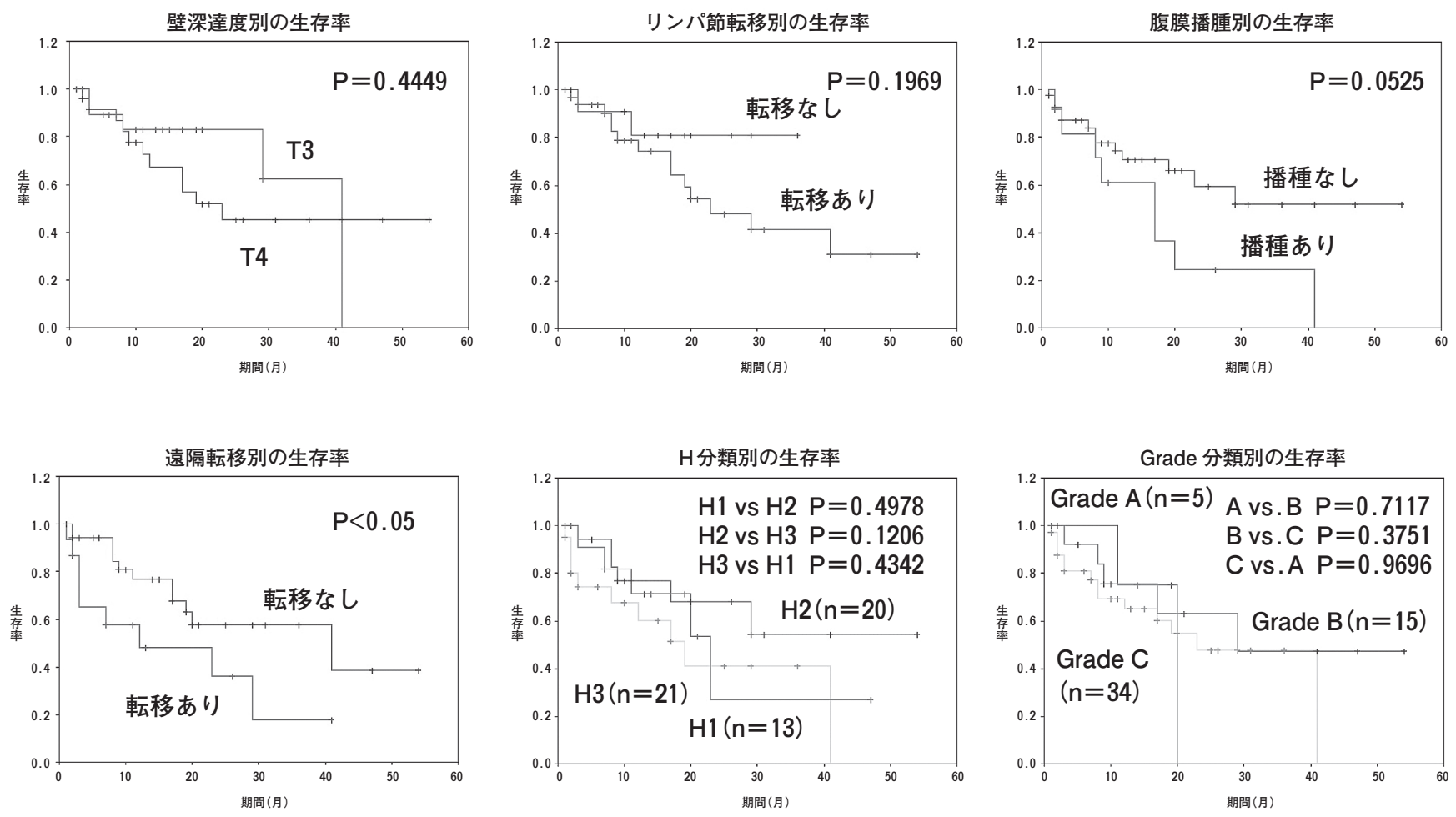

図 1 各種臨床病理学的因子と生存率 

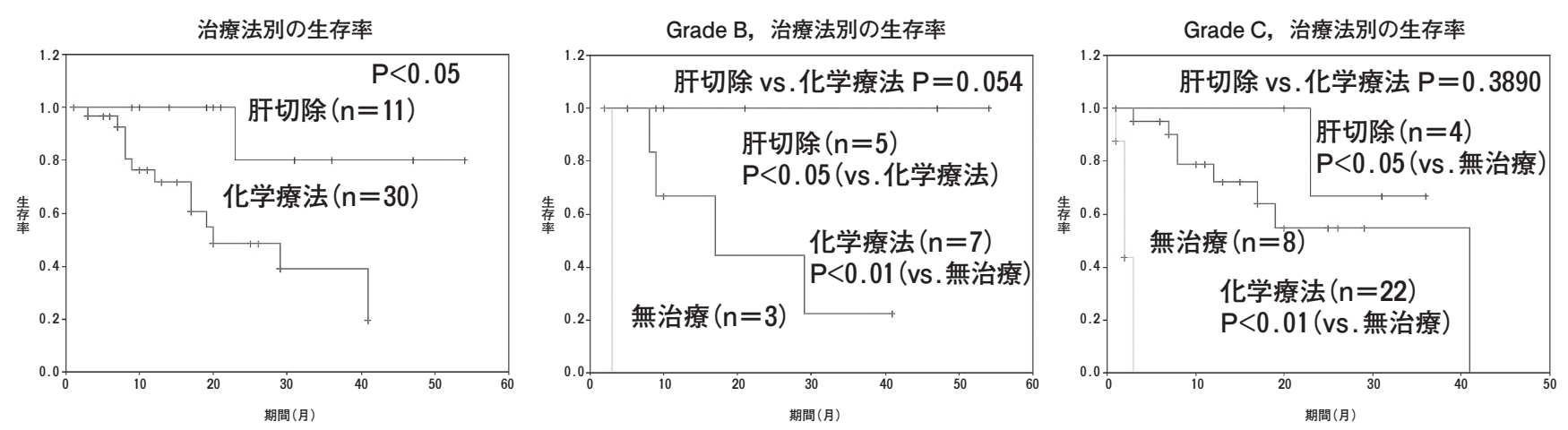

図 2 Grade 分類に基づく各種治療群の生存率

表 5 Grade 分類別各種治療法の生存率

\begin{tabular}{|ll|ccc|}
\hline & & Grade A & Grade B & Grade C \\
\hline 肝切除 + 化学療法 & 1 年生存率 & 100 & 100 & 100 \\
& 3 年生存率 & 100 & 100 & 66.7 \\
\hline 化学療法 & 1 年生存率 & 50 & 66.7 & 72.2 \\
& 3 年生存率 & 0 & 22.2 & 55.0 \\
\hline 無治療 & 1 年生存率 & 0 & 0 & 0 \\
& 3 年生存率 & 0 & 0 & 0 \\
\hline
\end{tabular}

(単位：\%)

残肝再発, 肝外再発の 3 因子が, 多変量解析では肝外再発 の有無のみがそれぞれ独立した予後規定因子として抽出さ れている ${ }^{2)}$. 当院の検討結果からは, 肝転移をきたしてい る症例の中でも, 肝外病変が存在する場合予後不良である ことが示唆されており，その予防策としての全身化学療法 の必要性は明らかである。また, 大腸同時性肝転移では, 原発巣の深達度が深く, リンパ節転移も高度で, 生物学的 悪性度が高く, 肝切除時に微小肝転移が存在する可能性が 高い.このことからも肝切除後に化学療法を行うことは理 にかなっており, 当院でも同時性肝転移に対する肝切除症 例では全例に術後化学療法を行っている。しかし, レジメ ンに統一性はなく, 種類, 組み合わせとも多種多様となっ ている(表 3 ). 肝転移切除後の補助化学療法に関する RCT が報告されたのは最近で，まだ少数である ${ }^{3,4}$.

一方, 近年, 大腸癌肝転移に対しての術前化学療法の有 用性について議論されている. 術前の化学療法の利点とし ては, 肝あるいは肝外の腫瘍縮小効果による手術機会の拡 大 (conversion therapy), 微小転移巣の早期治療による再 発の抑制（neoadjuvant chemotherapy）等がある. 当院で は 4 例に肝切除前の化学療法が施行されているが, うち 3 例は肝転移巣の縮小により肝切除可能となった。切除不能 進行・再発大腸癌に対する新規多剂併用化学療法の第 II, 正相試験において，切除不能と診断された高度肝転移例の
$3 \sim 22 \%$ で，肝転移巣が著明に縮小し手術可能となってい る ${ }^{5-7)}$. また, 高度な肝転移を有する症例でも, R 0 手術後 の 5 年生存率は $18 \%$ 程度期待できるとの報告もある ${ }^{8)}$ 。転 移性大腸癌に対する近年の化学療法の進歩は著しいが，い まだ確固たるエビデンスは示されてはいないというのが現 状であり,さらなるデー夕の蓄積が望まれる.

治療法による検討では, 肝切除群で化学療法に比し, 有 意に予後が延長し, Grade 別では Grade B において有意差 が認められた。手術適応と判断される時点である程度のバ イアスはかかっているにしても，手術拈よび化学療法によ り予後が有意に延長したということは手術可能症例に対し て肝切除を施行することは間違った治療法ではないと考え られ，大腸癌治療ガイドラインにも矛盾しない ${ }^{99}$ 。 大腸癌 肝転移に対して, 現時点では, 肝切除が最も効果的な治療 であることは明らかであり, 今後, 併用化学療法の研究に よりさらなる予後の改善が期待されるところである.

\section{結論}

大腸癌同時性肝転移症例の予後は遠隔転移の有無と治療 法に有意に左右され，治療法では特に Grade B 症例で「肝 切除 + 化学療法」が「化学療法単独」に比し有意に予後を 延長することが示唆された。

\section{文献}

1）河原正樹, 加藤知行, 森 武生, 望月英隆, 杉原健一, 亀岡信 悟, 亀山雅男, 小林 薰, 北條慶一, 武藤徹一郎：本邦に打ける 大腸癌同時性肝転移に対する治療の現況 (第 2 報) 一 全国アンケ 一下追跡調查結果. 日本大腸肛門病会誌（2003） 56，55-61.

2) 稲垣 優, 田辺俊介, 濱野亮輔, 西江 学, 徳永尚之, 常光洋 輔, 大塚眞哉, 三好和也, 岩垣博巳 : 大腸癌肝転移に対する肝切 除後の予後因子の解析. 日臨外会誌 (2009) 70，358-362.

3) Portier G, Elias D, Bouche O, Rougier P, Bosset JF, Saric J, Belghiti J, Piedbois P, Guimbaud R, Nordlinger B, Bugat R, Lazorthes $\mathrm{F}$, et al. : Multicenter randomized trial of adjuvant 
fluorouracil and folinic acid compared with surgery alone after resection of colorectal liver metastases : FFCDACHBTH AURC 9002 trial. J Clin Oncol (2006) 24, 4976-4982.

4 ) Nordlinger B, Sorbye H, Glimelius B, Poston GJ, Schlag PM, Rougier P, Bechstein WO, Primrose JN, Walpole ET, FinchJones M, Jaeck D, Mirza D, et al. : Perioperative chemotherapy with FOLFOX4 and surgery versus surgery alone for resectable liver metastases from colorectal cancer (EORTC Intergroup trial 40983) : a randomized controlled trial. Lancet (2008) 371, 1007-1016.

5 ) Saltz LB, Cox JV, Blanke C, Ronsen LS, Fehrenbacher L, Moore MJ, Maroun JA, Ackland SP, Locker PK, Pirotta N, Elfring GL, Miller LL: Irinotecan plus fluorouracil and leucovorin for meatstatic colorectal cancer. N Engl J Med (2000) 343, 905-914.

6 ) Tournigand C, Cervantes A, Fige Ar, Lledo G, Flesch M, Buyse M, Mineur L, Carola E, Etienne PL, Rivera F, Chirivella 1, Perez-Staub N, et al. : OPTIMOX1 : a randomized study of
FOLFOX4 or FOLFOX7 with oxaliplatin in a stop-and-go fashion in advanced colorectal cancer-a GERCOR study. J Clin Oncol (2006) 24, 394-400.

7 ) Falcone A, Ricci S, Brunetti I, Pfanner E, Allegrini G, Barbara C, Crino L, Benedetti G, Evangelista W, Fanchini L, Cortesi E, Picone $\mathrm{V}$, et al. : Phase III trial of infusional fluorouracil, leucovorin, oxaliplatin, and irinotecan (FOLFOXIRI) compared with infusional fluorouracil, leucovorin, and irinotecan (FOLFIRI) as first-line treatment for metastatic colorectal cancer: the Gruppo Oncologico Nord Ovest. J Clin Oncol (2007) 25, 1670-1676.

8 ) Elias D, Liberale G, Vernerey D, Pocard M, Ducreux M, Boege V, Malka D, Pignon JP, Lasser P : Hepatic and extrahepatic colorectal metastases: when resectable, their localization dose matter, but their total number has a prognostic effect. Ann Surg Oncol (2005) 12, 900-909.

9 ）大腸癌研究会編：大腸癌治療ガイドライン医師用 2010 年版, 大腸 癌研究会, 金原出版, 東京, 2005 pp 20-21. 